\title{
LA ESTRUCTURACIÓN AXIOLÓGICA DEL ORDEN \\ ECONÓMICO EN DEFENSA DE LA PROPIEDAD Y LA \\ LIBRE INICIATIVA. EL JUSTO EQUILIBRIO \\ HACIA EL DESARROLLO*
}

THE AXIOLOGICAL STRUCTURE OF ECONOMIC ORDER IN DEFENSE OF PROPERTY AND FREE ENTERPRISE. THE BALANCE TO DEVELOPMENT

L'ESTRUCTURATION DE L'ORDRE ÉCONOMIQUE DANS LA DÉFENSE DE LA PROPRIÉTÉ ET LA LIBRE ENTREPRISE. LE JUSTE ÉQUILIBRE POUR LE DÉVELOPPEMENT

Rodrigo Monteiro PessoA**

\begin{abstract}
RESUMEN
El Derecho Económico tiene un papel importante en la sociedad. Estructura el orden responsable por las reglas de producción de riquezas y su respectiva distribución, debiendo poseer instituciones fuertes para garantizar una mayor participación ciudadana en el crecimiento -y asi caminar hacia el desarrollo-, o centralizar el poder de tales instituciones políticoeconómicas para minimizar la distribución y acceso a la propiedad a una minoría, y así, caminar hacia el estancamiento. La propiedad, como institución jurídica, y la libre iniciativa como su actividad de exploración, tienen una especial trascendencia en esta estructuración axiológica, y es exactamente su fortalecimiento, objetivando el desarrollo, que vamos a delinear en este artículo.
\end{abstract}

PaLABRAS Clave: Derecho Económico - Orden económico - Propiedad - Desarrollo

ABSTRACT

Economic Law has an extremely important role in society. It structures the Economic Order responsible for the rules for the production of wealth and its respective distribution, so it must have strong institutions to ensure a greater participation of citizens in growth -thus heading towards development- or centralise the power of such political-economic institutions to minimise the distribution and access to property to a minority, thus heading towards stagnation. Property as a juridical institution and free initiative as its exploring activity have a special meaning in this axiological structure and its strengthening towards development, which we outline in this paper.

KEY WORDS: Economic law - Economic order - Property - Development

*Artículo recibido el 25 de septiembre de 2013 y aceptado para su publicación el 22 de abril de 2014.

* Licenciado en Administración en la Universidade Federal da Paraíba, Brasil. Licenciado en Derecho en el Instituto Superior de Educação da Paraíba, Brasil. Postgrado en Derecho de la Seguridad Social por Uniderp, Brasil. Magíster Académico en Derecho Económico por la Universidade Federal da Paraíba, Brasil. Doctorando en Derecho por la Universidad de Chile, correo electrónico: rodrigopessoa@hotmail.cl. 
RÉSUMÉ

Le droit économique a un rôle important dans la société. Il structure l'ordre responsable des règles de production de richesse et de sa répartition respective, et doit comprendre d'institutions fortes pour assurer une plus grande participation des citoyens à la croissance et donc vers le développement, ou de centraliser le pouvoir de ces institutions afin de minimiser la distribution et l'accès à la propriété à une minorité, et ainsi, marcher vers la stagnation. La propriété comme une institution juridique, et la libre entreprise en tant que son activité d'exploration, ont une importance particulière dans cette structure axiologique, et son renforcement, visant au développement, nous allons décrire dans cet article.

MOTS CLÉS: Droit économique - Ordre économique - Propriété - Développement

\section{INTRODUCCIÓN}

En el actual contexto global, el principal punto de argumentación política de los Estados se basa en el desarrollo de las naciones. Hacer que el progreso se vuelva real y satisfactorio es el objetivo mayor de todos los gobiernos. Sea para aumentar las riquezas en un contexto neoliberal o para que estas riquezas puedan favorecer a todos los ciudadanos a través de políticas públicas.

Independientemente del modelo político económico adoptado por el Estado, el desarrollo siempre está citado como meta.

Sin embargo, para que este objetivo sea cumplido, es necesario que el ordenamiento jurídico ofrezca herramientas de garantía, configurando las principales disposiciones jurídicas necesarias al mejor desempeño de la economía, de forma de respetar los derechos fundamentales involucrados en el sistema económico y también proteger al propio Estado del mal uso de la máquina pública cuando se dan los cambios de mando.

En este escenario, la propiedad y la libre iniciativa deben estar conceptualmente bien delineadas -ya que son instituciones fundamentales cuando el debate aborda el desarrollo-, y además debe existir la estructuración del orden económico de manera favorable a la comprensión holística del posicionamiento del Estado frente a la economía.

El derecho económico ejerce un papel fundamental en este contexto y, junto a la propiedad y a la libre iniciativa, debe ofrecer la tutela y estructuración del orden económico como única vía posible al desarrollo plural concreto.

Por esto, en este artículo propondremos conceptos para comprender cómo el Estado chileno debe estructurar su orden económico, teniendo en cuenta los elementos que consideramos más importantes en esta labor. Comencemos por la evolución e importancia del Derecho Económico, para comprender mejor esta disciplina, para luego estudiar la propiedad y la libre iniciativa como disposiciones del derecho chileno favorables a la construcción del desarrollo plural; luego explicaremos qué es este desarrollo plural, para finalmente sugerir cómo debe estar compuesto el orden económico en el país. 


\section{Antecedentes del Derecho Económico}

La economía siempre ha sido una de las mayores preocupaciones sociales desde el origen de los tiempos. Su papel en el direccionamiento al progreso es fundamental para los pueblos, y el dominio de sus matices es trascendental para el crecimiento de la riqueza.

En el siglo XVIII, cuando el mundo ha experimentado los cambios violentos de la Revolución Industrial, sustituyendo la mano de obra humana por la automatización, el capitalismo como sistema de producción ganó más espacio y, consecuentemente, los problemas sociales experimentaron nuevos rasgos, exigiendo una respuesta del Estado.

En este período, el Estado no podía hacer mucho a través del Derecho. Eso porque la estructura del Derecho Civil y Comercial no era suficientemente fuerte para regular los mercados, y así, no hubo otra alternativa que optar por el liberalismo económico.

A la mitad del siglo XIX, cuando el capitalismo pasa a tener una organización colectiva -saliendo del capitalismo aislado, donde cada país se interesaba y era básicamente afectado solamente por sus decisiones económicas- recibe aún mayor fuerza teórica y práctica el Derecho Económico. La concentración capitalista es el fenómeno decisivo del derecho económico. Es ella que está en el origen de todas las grandes mutaciones de las sociedades industriales: la intervención del Estado (...) es una consecuencia de esta concentración ${ }^{1}$.

En el inicio del siglo XX, la Primera Guerra Mundial fue responsable de cambios sociales, políticos, económicos y jurídicos grandiosos. La destrucción económica de Alemania de postguerra ha posibilitado el desarrollo de nuevos pensamientos sobre el Derecho Económico, tales como el de Justus Wilhelm HedEMAnN y Gustav RADBRUCH. Además, en este periodo, surgen constituciones que responden a las nuevas exigencias globales, como la de México (1917) y la de Weimar (1919).

El capitalismo como sistema de producción ha recibido muchas críticas por teóricos como Karl MARX y Friedrich ENGELS, a fines del siglo XIX, ya que produjo muchas desigualdades sociales. Estos autores sostenían que el Estado debe intervenir en la economía, regulándola. Empero, afirmaron que el Estado también debería ser el dueño de los medios de producción.

Sin entrar en los problemas de tales conjeturas, es importante señalar que a través de este pensamiento se desarrollan las líneas iniciales del Derecho Económico, que aparece inicialmente en los Estados socialistas, para posteriormente ser delineado en los Estados que adoptaban el sistema de producción capitalista.

Por ende, el fin de la Segunda Guerra Mundial fue un nuevo hito para este novedoso Derecho, ya que el bloque socialista inició una serie de medidas cam-

${ }^{1}$ FarJat, Gérard (1982). Droit Economique. Paris: Presses Universitaires de France, 2e édition, p. 143. (Traducción del autor). 
biantes del sistema de producción, surgiendo reglas que le modificarían y harían que los demás países pudiesen al menos repensar la forma como el Estado se pone delante los problemas económicos ${ }^{2}$.

La libertad de empresa y la explotación de la propiedad particular generan el gran conflicto entre el ciudadano y el Estado. Luego, la mediación de los intereses originarios de tales relaciones sociales lleva a la judicialización del factor económico, adecuándolo a las nuevas instituciones ideológicas creadas por los particulares en su libre iniciativa, para que no haya abusos en la explotación de la propiedad.

Cuando la propiedad (como institución jurídica) está regulada de manera de permitir inclusión social e igualdad de acceso, las innovaciones, inversiones y ganas de producir son factores presentes entre los ciudadanos, forjando mayor crecimiento y desarrollo de la nación. Esta es la opinión de Daron ACEMOGLu y James RoBINSON, que será mejor aclarado más adelante.

\section{EVOLUCIÓN DEL CONCEPTO DE PROPIEDAD}

La palabra propiedad viene del proprietas, de Proprius, que significa, por lo tanto, la calidad de lo que es propio. La propiedad ha pasado por varias etapas: el poder absoluto en Roma, la visión liberal de la Revolución Francesa (1789) y el Código de Napoleón (1804), y el diseño del Estado Socialista Soviético (1917) y de la doctrina social cristiana, que tiene como eje la encíclica del Papa León XIII, Rerum Novarum (1891) ${ }^{3}$. Todas estas etapas han cambiado su concepto, de acuerdo con el momento social de la historia, hasta llegar a la función social, es decir, al relativismo del dominio absoluto para promover el bienestar general.

Se puede decir que a partir de la Revolución Francesa la propiedad gana caracteres más modernos dentro de la perspectiva liberal-individualista, convirtiéndose en derecho natural inherente al hombre. Dominus unus, unum dominium ${ }^{4}$. De la misma manera lo ha hecho la Declaración de Derechos de Virginia de 1776, disponiendo en su artículo primero que todos los hombres son por naturaleza igualmente libres e independientes, y tienen ciertos derechos inherentes, de los cuales, cuando entran en un estado de sociedad, no pueden ser privados o postergados; expresamente, el gozo de la vida y la libertad, junto a los medios para adquirir y poseer propiedades, y la búsqueda y obtención de la felicidad y la seguridad.

En la Declaración de los Derechos del Hombre y del Ciudadano de 1789, procedente de la Asamblea Nacional de la Revolución Francesa, en el artículo XVII se encuentran similitudes con el texto de la Declaración de Virginia, el apoyo a la idea de la propiedad como un derecho innato, siendo inviolable y sagrado

\footnotetext{
${ }^{2}$ Los equívocos y problemas generados con la política soviética no serán objeto de estudio de este trabajo.

${ }^{3}$ Almeida, Washington (2006). Direito de propriedade: limites ambientais no código civil. Barueri (São Paulo): Manole, pp. 16 y 17.

${ }^{4}$ Hay un solo Señor y un solo dominio. (Traducción del autor).
} 
el derecho de propiedad, nadie podrá ser privado de él, excepto cuando la necesidad pública, legalmente comprobada, lo exige de manera evidente, y a la condición de una indemnización previa y justa.

En la Declaración Universal de los Derechos Humanos, aprobada por resolución de la tercera reunión ordinaria de la Asamblea General de las Naciones Unidas, en los artículos 17.1 y 17.2 tenemos: Toda persona tiene derecho a la propiedad, individual y colectivamente. Nadie será privado arbitrariamente de su propiedad. Por último está el artículo 544 del Código de Napoleón que establece que la propriété est le droit de jouir et disposer des choses de la manière la plus absolute, porvu qu'on n'en fasse pas un usage prohibé par les lois ou par les règlements'.

El triunfo capitalista con énfasis en la propiedad privada es la Revolución Industrial. Durante este período, el sistema capitalista fuerza el principio de apropiación privada de los medios de producción. Estos medios se concentran en las manos de la gente que en general no actuará en el proceso de producción dirigido al resultado final. Hay una distinción entre la propiedad, los medios de producción y ejecución del trabajo ${ }^{6}$.

El derecho de propiedad no puede más ser considerado como absoluto, ya que le fue añadido un concepto paralelo que limita su poder de libre uso, goce y disfrute. Este concepto paralelo es la función social, que se realiza a través de la correspondencia entre los regímenes político y económico. Si se desea cambiar la naturaleza del poder político, también hay que modificar el régimen de las propiedades y, por ende, crear nuevos modelos económicos. Y si hoy se busca la eficiencia socialdemócrata, basada en la promoción del Estado de Bienestar Social, éste es el diseño que debe arraigar la propiedad. Georges RIPERT dice que los derechos no se otorgan a los hombres, sino para permitir que se cumpla su función en la sociedad. No hay ninguna razón para concederles derechos que les permitieran sustraer el uso común de bienes útiles a todos ${ }^{7}$.

El derecho chileno promulgó originariamente en el Código Civil de Andrés Bello de 1855, el derecho de propiedad en su artículo 582, que mantiene la misma redacción hasta los días actuales, diciendo que "el dominio (que se llama también propiedad), es el derecho real en una cosa corporal, para gozar y disponer de ella arbitrariamente; no siendo contra ley o contra derecho ajeno"s.

\footnotetext{
${ }^{5}$ La propiedad es el derecho de gozar y disponer de las cosas de la manera más absoluta, desde que no se haga un uso prohibido por las leyes o reglamentos. (Traducción del autor).

${ }^{6}$ Silva Otero, Aristídes (2005). La llamada revolución industrial. Caracas: Universidad Católica Andrés Bello, p. 185.

${ }^{7}$ Le régime démocratique et le droit civil, apud PACHECO, Wellington (1984). "A propriedade agrária e seu novo conceito jurídico constitucional". Revista Ajuris (Associação dos Juízes do Rio Grande do Sul), No 32, Año XI, Porto Alegre: Ajuris.

${ }^{8}$ Caldera, Rafael (1981). "Código Civil de la República de Chile”. En: Obras completas de Andrés Bello, Tomo XIV, Caracas: Fundación La Casa de Bello, p. 409.
} 
Desarrollando el concepto de propiedad en un significado moderno, y de acuerdo a las exigencias de bienestar de la Constitución de la República de Chile de 1980 , tenemos en su artículo 19 , número 24 , incisos $1^{\circ}$ y $2^{\circ}$, que "la Constitución asegura a todas las personas el derecho de propiedad en sus diversas especies sobre toda clase de bienes corporales o incorporales. Sólo la ley puede establecer el modo de adquirir la propiedad, de usar, gozar y disponer de ella y las limitaciones y obligaciones que deriven de su función social. Esta comprende cuanto exijan los intereses generales de la Nación, la seguridad nacional, la utilidad y la salubridad públicas y la conservación del patrimonio ambiental". Cuando se señala la función de la propiedad, inmediatamente tenemos la idea de actuar con un propósito para cumplir con una obligación, un papel.Ese propósito es la función social, es decir, el cumplimiento de esta tarea en beneficio de la comunidad, exactamente como fue propuesto por Georges RiperT y que sigue con las ideas de Fernanda de Salles Cavedon:

El Estado contemporáneo, comprometido con la realización de una función social, principalmente a través del estilo constitucional inaugurado con la Constitución de Weimar, dio lugar a una contracción de la esfera del Derecho Privado, cuyas categorías nucleares, entre las cuales la Propiedad, han sido marcadas por un carácter social. Desde este hito histórico, se inaugura una nueva fase del Derecho, ahora comprometido con el Interés Público, mediante la limitación de las libertades individuales y de la noción de los derechos/ función. Por lo tanto, la Propiedad del Derecho contemporáneo aparece como la Propiedad Función Social/Ambiental.

Obviamente, cuando se trata de la función social de la propiedad, hay una referencia directa a la propiedad privada, porque la propiedad pública ya tiene su carácter social por naturaleza. En este punto de vista, el objetivo es proporcionar una limitación razonable de los derechos y libertades de los demás, garantizando el acceso igualitario a los bienes y posibilitando el crecimiento individual del ciudadano al mismo tiempo. Y así, satisfacer las exigencias morales necesarias para el bienestar colectivo.

La Convención Americana sobre Derechos Humanos (Pacto de San José, Costa Rica), ratificada por Chile en 1990, en su capítulo V, artículo 32, establece que "toda persona tiene deberes para con la familia, la comunidady la humanidad. Los derechos de cada persona están limitados por los derechos de los demás, por la seguridad de todos y por las justas exigencias del bien común, en una sociedad democrática".

Hasta hoy mucho se ha dicho sobre la función social y uno se pregunta: ¿cómo es posible verificar que la propiedad cumple con su función social? Para responder a esta pregunta se recurre a la doctrina de Clarissa FerReira Macedo y Cyro Luiz Pestana PúPERI que dialogan en la misma dirección. La función social de la

\footnotetext{
${ }_{9}^{9}$ De Salles Cavedon, Fernanda (2003). Função social e ambiental da propriedade. Florianópolis: Momento Atual, p. 27. (Traducción del autor).
} 
propiedad debe ser verificada a través de un trípode, como el desarrollo (según especificaremos más adelante). Este trípode se refiere a la función social, la función económica (en sentido estricto) y la función ambiental de la propiedad.

Cyro Luiz ${ }^{10}$ indica que la propiedad bien utilizada en la perspectiva social puede llegar a varias áreas, tales como la laboral (cuando se ofrece la posibilidad de crecimiento a través de la generación de empleo y renta), el favorecimiento de las políticas públicas (como generadora de recursos para la atención de la salud, asistencia social, educación y el bienestar urbano a través del pago de impuestos), y el bienestar social digno (cuando una empresa ofrece a través de sus productos y servicios los bienes necesarios y suministros esenciales para la vida social; cumpliendo con la responsabilidad sobre lo que vende, incluyendo la protección de los derechos de los consumidores).

En la perspectiva de la función económica de la propiedad, el mismo autor comenta que aunque la productividad es indispensable para el cumplimiento de la función social, en el campo económico, otros elementos, se muestran imprescindibles al cumplimiento de la función social, como la generación de riqueza, no sólo para el propietario o el empleado directamente vinculados a la actividad, pero sobre todo para la sociedad, en el desarrollo del comercio, en el pago de impuestos, y en la creación de oportunidades laborales ${ }^{11}$.

A pesar de todas las críticas que existen en la teoría utilitarista aplicada a la propiedad, ella también es una buena respuesta que ofrece herramientas importantes a la aplicación económica en la función social. El utilitarismo es una filosofía moral consecuencialista, es decir, que juzga lo correcto o incorrecto de las acciones o las reglas o instituciones por la bondad y la maldad de las consecuencias que traen consigo. El utilitarismo evalúa la bondad o maldad de las consecuencias en términos de su tendencia a maximizar la utilidad o bienestar ${ }^{12}$. Los padres del utilitarismo lo pensaron principalmente como un sistema de decisiones políticas y sociales, oponiéndose a un sistema de moralidad personal. La evaluación utilitarista se puede dividir en dos preguntas relacionadas: 1) la forma de definir el bien (o utilidad) a la que los tomadores de decisiones sociales deben apuntar y 2) la forma de agregar experiencias individuales en la utilidad con el fin de evaluar las consecuencias generales de opciones sociales ${ }^{13}$.

Uno de los teóricos del utilitarismo, Jeremy BENTHAM, afirmaba, por ejemplo, que la fórmula ideal utilitarista apunta que en un estado de cosas en las

\footnotetext{
${ }^{10}$ PúPERI, Cyro Luiz Pestana (2008). "A função social, econômica e a preservação do meio ambiente como condições limitadoras do direito de propriedade”. Artículo del Juris Plenum Ouro, No 1, mayo de 2008. En: Juris Plenum Ouro, No 18, marzo de 2011. DVD.

${ }^{11}$ Púperi (2008). (Traducción del autor).

${ }^{12}$ Alexander, Gregory y Peñalver, Eduardo (2012). An introduction to property theory. Cambridge: Cambridge University Press, p. 11.

${ }^{13}$ Alexander y Peñalver (2012), p. 12.
} 
que hay más placer total, pero donde una pequeña élite disfruta de todo el placer, debe ser preferible a un estado de cosas en el que hay un poco menos de placer total, pero donde todo el mundo lo disfruta por igual. En la economía del bienestar, un concepto análogo al de BENTHAM se refleja en la eficiencia de KaLDOR-Hicks ${ }^{14-15}$.

COOTER y UlEn, igualmente establecen que el derecho de propiedad provee el marco legal para la asignación de los recursos y la distribución de la riqueza ${ }^{16}$. Además, comentan que las sociedades crean la propiedad como un derecho legal para estimular la producción, desalentar el robo y reducir los costos de proteger los bienes ${ }^{17}$. De esta forma, uno de los objetivos claros del derecho de propiedad es estimular la producción, haciendo que la sociedad pueda disfrutar de un mayor incremento de la riqueza total. Luego, siempre que el uso de la propiedad pueda generar una situación donde alguien mejore sin que los demás empeoren, y que -más aún- proporcione la mejor producción de riqueza posible, desde una perspectiva colectiva, esta propiedad cumple con su función económica.

La función ambiental de la propiedad es aquella donde se puede concretar el contenido del artículo 19, No 8 de la CPR de 1980. Determina que existe "el derecho a vivir en un medio ambiente libre de contaminación". Y que "es deber del Estado velar para que este derecho no sea afectado y tutelar la preservación de la naturaleza. La ley podrá establecer restricciones especificas al ejercicio de determinados derechos o libertades para proteger el medio ambiente". Incluso, el artículo 20, inciso $2^{\circ}$ garantiza el uso del Recurso de Protección al afectado en su derecho a vivir en un ambiente libre de contaminación.

Es decir, la propiedad, si bien productiva, debe preservar el ambiente saludable a todos, preservando los ecosistemas involucrados para las generaciones presentes y futuras. Por tanto, se interconectan fácilmente los tres conceptos para que -a través de la gestión ambiental para el desarrollo sostenible, la promoción del bienestar social y del uso racional para el desarrollo de la actividad económica- pueda alcanzar los verdaderos objetivos de los intereses difusos en términos de calidad de vida saludable.

En Chile existen dos disposiciones jurídicas que hablan del derecho de propiedad. Una de ellas en el Código Civil de 1855, y la otra en la Constitución de 1980. En ellas es interesante notar que el Código Civil tiene fuertes características decimonónicas, con enérgica influencia de la Declaración de los Derechos del Hombre y del Ciudadano de 1789, lo que demuestra los rasgos liberales,

\footnotetext{
${ }^{14}$ Alexander y Peñalver (2012), p. 14.

${ }^{15}$ La eficiencia de KALDOR-Hicks ya fue analizada en informes pasados, por lo que nos abstenemos de hacer nuevas consideraciones en esta oportunidad.

${ }^{16}$ Cooter, Robert y Ulen, Thomas (2008). Derecho y economía. México: Fondo de Cultura Económica, $2^{\text {a }}$ edición, p. 113.

${ }^{17}$ Cooter y Ulen (2008), p. 127.
} 
delineando un derecho subjetivo cuasi absoluto, contenido en la redacción del artículo 582: "el dominio (que se llama también propiedad), es el derecho real en una cosa corporal, para gozar y disponer de ella arbitrariamente; no siendo contra ley o contra derecho ajeno".

La doctrina clásica apunta que el concepto de dominio/propiedad del Código de Bello contiene cuatro características básicas: es un derecho real (porque se ejerce sobre una cosa, es un derecho in re), es un derecho absoluto (ya que su titular puede hacer uso de su propiedad sin rendir cuenta a nadie por eso), es un derecho exclusivo (porque solo le compete el uso y el goce a la persona que es dueña de la cosa y nadie puede oponerse a este uso y goce; y dentro de este concepto individualista el propietario tiene el perfecto derecho para impedir que nadie venga a gozar de una cosa ajena, aunque no cause daño), y es un derecho perpetuo (no se extingue con el tiempo $)^{18}$. Y con esto se comprueba la positivación de un derecho de propiedad análogo al Code, trayendo fisionomías similares a las contenidas en el Código napoleónico de 1804.

Ya la CPR abarca una cierta evolución conceptual, añadiendo la función social de la propiedad, mismo siendo una Constitución Política con matices también liberales. En el artículo 19, No 24, incisos $1^{\circ}$ y $2^{\circ}$ vimos anteriormente que la Constitución expresamente habla de la función social que comprende "los intereses generales de la Nación, la seguridad nacional, la utilidad y la salubridad públicas y la conservación del patrimonio ambiental".

Estas dos disposiciones componen el trayecto evolutivo del concepto de derecho de propiedad chileno, pues representan dos momentos distintos en la historia, pero que comparten la existencia legal con validez y eficacia en el ordenamiento jurídico actual. Según Eduardo CORDERO:

La evolución del derecho de propiedad en Chile puede establecerse en tres etapas: a) la primera, que corresponde a la forma de propiedad liberal-burguesa, que va desde la Constitución de 1833, con la sanción del Código Civil de 1855 hasta la sanción de la Constitución de 1925; b) la segunda, comprende el período de la propiedad como función social, que comienza a delinearse a partir de la Constitución de 1925 y que es perfectamente configurada con la modificación constitucional de 1967; c) la tercera, que es el modelo de propiedad en la actualidad vigente en la Constitución de 1980, caracterizada por su concepción subjetivista, el resguardo de sus facultades o atributos esenciales y su ampliación a todo espectro de bienes, sean corporales o incorporales ${ }^{19}$.

\footnotetext{
${ }^{18}$ Alessandri Rodríguez, Arturo (1937). Derecho Civil. Tomo II, Santiago: Zamorano y Caperán, p. 25.

${ }^{19}$ Cordero Quinzacara, Eduardo (2006). "La dogmática constitucional de la propiedad en el derecho chileno". Revista de Derecho (Valdivia), Vol. 19, No 1, pp. 125-148. Disponible en: <http://www.scielo.cl/ scielo.php?pid=S0718-09502006000100006\&script=sci_arttext $>$ [Consulta 30 diciembre 2013].
} 
El derecho de propiedad tiene dos aspectos: objetivo y subjetivo. En Chile es posible afirmar que predomina la concepción subjetiva ${ }^{20}$, ya que la Carta Magna adopta un concepto unitario con una visión unidimensional de los derechos, haciendo que su construcción se dé en situaciones jurídicas concretas ${ }^{21}$.

Parte de la doctrina adopta el concepto de garantías de instituto, originario del derecho alemán, y desarrollado por Carl ScHMiTt. Es cierto que en la génesis de la Constitución de 1980 en Chile, existe gran influencia de la doctrina de Sснмітт, por lo que esta concepción puede ayudar en el desarrollo de una visión más coherente de la materia, también para el caso chileno.

Una garantía institucional supone la existencia de una institución, esto es, una entidad formada y organizada por el derecho público, y por ello delimitable y distinguible. Este tipo de garantía se refiere siempre a algo actual, presente, formado y organizado, existente y disponible. En esta medida radica en ella la garantía de un determinado estado y una situación normativa existente, y contiene elementos de una garantía de statu quo ${ }^{22}$.

Esta idea incorpora como elemento la garantía dentro del ordenamiento jurídico y no frente al ordenamiento jurídico ${ }^{23}$. Ofrecen un ámbito de libertad pero contenida en un paradigma público, que puede limitarlo y reglamentarlo.

De ahí surge la estructura de la garantía constitucional del derecho de propiedad, que comprende cinco aspectos: a) el derecho de propiedad en sí, asegurado en el artículo 19, número 24, inciso $1^{\circ}$ de la CPR de 1980; b) los derechos subjetivos que puede alegar el titular de un derecho real de propiedad (específicamente en el inciso $3^{\circ}$ del artículo 19 , No 24, cuando abarca los requisitos para la expropiación); c) el principio de la legalidad en la regulación de la propiedad; d) los parámetros dentro de los cuales deberá moverse el legislador al regularla; y e) los elementos constitutivos del concepto tradicional del derecho de propiedad como derecho real sobre cosas corporales (uso, goce y disposición) ${ }^{24}$.

Esta delimitación es una construcción doctrinal, ya que en el análisis de la jurisprudencia del Tribunal Constitucional en recursos de inaplicabilidad y de la Corte Suprema en casos de recurso de protección, Jessica FuENTES llega a la con-

\footnotetext{
${ }^{20}$ De manera tradicional se ha considerado que el orden jurídico está integrado por dos sistemas: el de las leyes o normas jurídicas consideradas en sí mismas o derecho objetivo y el sistema de los derechos subjetivos. Sobre estos último se dijo que son poderes con los que el hombre viene al mundo, anteriores al orden jurídico, o derecho objetivo y este simplemente cumple con la tarea de reconocerlos o garantizarlos. En: Rосна ОсноA, Cesáreo (2006). Manual de introducción al derecho. Colección Lecciones de jurisprudencia, Bogotá: Editorial Universidad del Rosario, 1a edición, p. 227.

${ }^{21}$ Cordero Quinzacara (2006).

${ }^{22}$ Aldunate Lizana, Eduardo y Fuentes Olmos, Jessica (1997). "El concepto de derecho de propiedad en la jurisprudencia constitucional chilena y la teoría de las garantías del instituto". En: Revista de Derecho de la Pontificia Universidad Católica de Valparaíso, Vol. XVIII, p. 206.

${ }^{23}$ Aldunate y Fuentes (1997), p. 212.

${ }^{24}$ Aldunate y Fuentes (1997), p. 214.
} 
clusión de que no existe un concepto claro de lo que es el derecho de propiedad en su sentido constitucional, ni del preciso alcance y extensión de las garantías constitucionales que lo amparan ${ }^{25}$.

En un texto posterior, del año 2006 (postreforma constitucional que ha atribuido nuevos rasgos al Tribunal Constitucional en Chile), Eduardo CORDERO, aún sustenta la misma opinión de antaño arguyendo que el examen de las soluciones doctrinales y jurisprudenciales a las que se ha llegado en Chile nos lleva a concluir la necesidad urgente de formular una reconstrucción dogmática del contenido prescriptivo del artículo $19 N^{\circ} 24$ CPR, que nos permita comprender mejor el conjunto de garantías que establece, sus alcances y sentido dentro del Texto Constitucional, así como el objeto hacia el cual se encuentran orientadas ${ }^{26}$.

La existencia de un concepto concreto de propiedad con sus alcances y matices es demasiado importante para la sistematización del ordenamiento jurídico, que favorecerá la participación ciudadana en el desarrollo del país, teniendo presente cómo el individuo debe manejar su propiedad (asociado a qué factores, como la función social, por ejemplo), y conociendo las garantías existentes para hacer valer este derecho.

En el ordenamiento jurídico chileno, la propiedad está garantizada por el Recurso de Protección (artículo 20 de la CPR), lo que de cierta manera corrobora con nuestra posición de defensa de la propiedad como un derecho fundamental.

La propiedad puede ser considerada como un derecho natural ${ }^{27}$, y con este matiz se comprende aún como una derivación inmediata del principio de autonomías sociales $^{28}$. La propiedad es un reflejo de la manifestación humana en la comunidad, es la expresión máxima de la autonomía de la voluntad y es corolario de la libertad, siendo, entonces, un derecho humano y fundamental en la clasificación jurídica moderna. Carlos RuIz-Tagle ViaL también comprende que el

\footnotetext{
${ }^{25}$ Aldunate y Fuentes (1997), p. 203.

${ }^{26}$ Cordero Quinzacara (2006).

${ }^{27}$ Derecho natural visto desde el punto de vista jurídico, de la existencia de un orden jurídico-natural dotado de diversos elementos que se verifican y se implementan según el fin del Derecho en la sociedad. Si la propiedad es una expresión de la autonomía de la voluntad, y con ella se busca la autoexpresión del hombre en la búsqueda de sus satisfacciones personales en el grupo social, a partir del momento en que el Derecho desea tutelar esta manifestación humana, incorporando a su estructura esta finalidad de protección de los bienes corporales e incorporales que se adhieren al patrimonio de las personas, este fin natural es parte indisociable del orden jurídico-natural, por lo tanto, la propiedad puede ser concebida como un derecho natural. Ver otras concepciones en Areitio Rodrigo, Ramón (1996). Derecho Natural. Lecciones elementales. Bilbao: Universidad de Deusto, Serie Publicaciones de la Universidad de Deusto, pp. 1 y ss.

${ }^{28}$ Fermandois VöHringer, Arturo (2011). Derecho Constitucional Económico: Garantías económicas, doctrina y jurisprudencia. Tomo I, Santiago: Ediciones Universidad Católica de Chile, 2a Edición actualizada, p. 110.
} 
desconocimiento de la propiedad privada ha sido universalmente comprobado como la extinción de las libertades ${ }^{29}$.

PATTERSON comenta que un valor surge, se lo construye socialmente, sólo cuando una masa crítica de personas, o una minoría poderosa, lo comparte, se conduce de modo persistente de acuerdo con ély lo convierte en normativo ${ }^{30}$. La propiedad-relacionada con la libertad-se ha vuelto normativa por una persistente conducta de protección de los bienes en la historia.

El hombre siempre vivió en sociedad y la mejora de la vida comunitaria es lo que originó al Estado, que puede ser comprendido como una reunión de un grupo específico para el bien común a través de una coordinación de esfuerzos y una cooperación mutua organizadas ${ }^{31}$. Luego, facilitar la protección de la esfera personal con la presencia del Estado es una de las justificaciones para que el hombre haya echado mano de una parte de su libertad para que pudiese estar bajo la tutela de este ente ficticio, y así recibir un mayor resguardo.

CoOTER y Ulen también afirman que en un 'estado de naturaleza' los hombres tendrían que destinar recursos para proteger su propiedad contra los demás, lo que generaba un desperdicio. Mientras tanto, en un régimen estatal donde exista la protección de la propiedad, los recursos que serían destinados a la protección de los bienes pueden ser invertidos de otras formas, asignando de mejor manera la riqueza y optimizando la destinación económica basada en la eficiencia. Es decir, para los autores estadunidenses, las sociedades crean la propiedad como un derecho legal para estimular la producción, desalentar el robo y reducir los costos de proteger los bienes ${ }^{32}$.

El hecho de que una propiedad sea un derecho natural le concibe el estatus de derecho humano, o sea, la noción de derecho "mínimo" otorgado por la exclusiva calidad de ser humano, caracterizado por el reconocimiento de su aplicación universal y de su fuerza superior a cualquier otra norma. La unanimidad se llama implícitamente como la fuente de legitimidad de estos derechos. Incluso es posible encontrar referencias textuales que apuntan a las influencias divinas o religiosas en los derechos naturales/humanos, pero ellos se distinguen de la regla religiosa por tener carácter universal ${ }^{33}$. Frente al Estado moderno, los derechos del hombre o los derechos naturales irán adoptando progresivamente el carácter de limitaciones al poder del Estado, desempeñando un papel característico en la construcción del estado constitucional de derecho ${ }^{34}$.

\footnotetext{
${ }^{29}$ Ruiz-Tagle Vial, Carlos (2013). Curso de Derecho Económico. Santiago: Librotecnia: 2a edición actualizada y aumentada, p. 206.

${ }^{30}$ Ruiz-Tagle Vial (2013), p. 77.

${ }^{31}$ Azambuja, Darcy (2001). Teoria Geral do Estado. São Paulo: Editora Globo, p. 3.

${ }^{32}$ Cooter y Ulen (2008), p. 127.

${ }^{33}$ En AbatI, Riccardo (2012). Storia dei diritti umani. Padova: GOODmood, 1 edizione, pp. 64 y 65.

${ }^{34}$ Prado D., Maximiliano (2007). "Limitación de los Derechos Humanos: Algunas consideraciones teóricas”. Revista Chilena de Derecho, Vol. 34, No 1, pp. 61-90. Disponible en: <http://www.scielo.cl/scielo. php?script=sci_arttext\&pid=S0718-34372007000100005\&lng=es\&nrm=iso > [Consulta: 15 enero 2015].
} 
Ya los derechos fundamentales son el reconocimiento y estructuración -por parte de las constituciones- de los derechos humanos, positivándolos para otorgarles protección bajo el ordenamiento jurídico, a través de un sistema de garantías propias $^{35}$. Por ende, al poner el derecho de propiedad en el rol de derechos fundamentales de la Constitución de la República de Chile de 1980, existe el reconocimiento de la propiedad como derecho fundamental y, consiguientemente, como derecho humano/natural, ya que éste es el papel de los derechos fundamentales. Este rasgo jurídico debe ser visto tal y cual como un derecho fundamental en las actuaciones de los tribunales, siempre teniendo en cuenta que en las causas en que la propiedad está siendo discutida, el criterio a ser utilizado es el criterio de ponderación entre derechos fundamentales. Solamente así, en Chile será posible verificar la presencia de una sociedad inclusiva y protectora de los derechos humanos en materia económica.

\section{LA LIBRE INICIATIVA EN EL CONTEXTO SOCIOECONÓMICO}

El próximo punto importante que debe ser abordado en este análisis de la estructuración axiológica del orden económico para proteger la propiedad y caminar hacia el desarrollo es la libre iniciativa. Ésta es la garantía ofrecida por el Estado en la explotación de la propiedad para que su dueño pueda generar más riqueza a su patrimonio. De nada valdría garantizar el derecho de propiedad si su dueño no la pudiese explorar.

Según verificamos en el estudio conceptual de la propiedad -que salió a la luz con el ascenso de la burguesía como clase social dominante en los siglos XVIII y XIX-su carácter absoluto se erigió hasta la concepción de un derecho sagrado e inviolable como lo demuestra el análisis del artículo 17 de la Declaración de los Derechos del Hombre y del Ciudadano de 1789.

\footnotetext{
${ }^{35}$ Hay teorías contrarias, como la de Luigi Ferrajoli, que no considera el derecho de propiedad como un derecho fundamental, por el hecho de que, siendo un derecho fundamental la positivación de un derecho humano, la estructura de la propiedad es muy diferente de la estructura de los derechos humanos. Por ejemplo, el derecho de disponer de la propiedad, siendo un derecho negociable y vendible, mientras que los derechos humanos son inalienables. Otra diferencia de estructura señalada por Ferrajoli, es que el derecho de propiedad es exclusivo, es decir, un derecho asignado que excluye a todos los demás, mientras que los derechos humanos son universales. Por fin, el hecho de que los derechos humanos promueven la igualdad entre las personas, mientras que la propiedad promueve la desigualdad jurídica basada en la excludendi alios. Para mejor análisis, ver Liguori, Alfonso (2009). "La teoria dei diritti fondamentali di Luigi Ferrajoli: Considerazioni epistemologiche e politiche". In: Jura Gentium. Rivista di filosofia del diritto internazionale e della politica globale. Disponible en: <http://www.juragentium.org/topics/rights/it/liguori. htm> [Consulta: 15 enero 2014].

Empero, aquí hay una confusión entre el derecho en sí mismo y el objeto del derecho. Cada derecho fundamental tiene su contenido jurídico, en que se delimita el contenido esencial (que no debe ser violado en la relativización del derecho), y el hecho de que la propiedad pueda ser negociada, vendible y de ella se pueda disponer, no le quita el rasgo de derecho fundamental. Hasta porque, hoy día, muchos ordenamientos que protegen el derecho a la vida en el rol de derechos fundamentales, de otra parte permite el aborto o la eutanasia. Ni por eso la vida ha perdido su característica de derecho humano/natural.
} 
En esta época, el uso de la propiedad se relacionaba con la separación de las esferas pública y privada, ya que el Estado se abstuvo de cualquier oposición al control que las monarquías absolutistas ejercían sobre el comercio. Es decir, el Estado debería comprometerse con la política, con las cuestiones de la esfera pública, y la sociedad civil debería ocuparse de las actividades particulares, especialmente económicas. Esta es la libertad negativa que garantiza al dominus el impulso de la propiedad separada de cualquier obligación social en la generación de nuevas riquezas.

Consecuentemente, el Estado no debería interferir, o si lo hace que sea lo mínimo inevitable, pues siendo una doctrina liberal la defensa de la propiedad privada -cuyo principio se sostiene en el lucro- es desarrollada libremente por el espíritu competitivo y emprendedor de cada uno. Es evidente que el Estado seguía siendo un mero espectador de la economía, y se limitó a observar su desarrollo a través de la habilidad que cada propietario tuvo para transformar su dinero en otros bienes y, por tanto, en más riqueza.

Al mismo tiempo, el liberalismo abogaba por la creación de instituciones para dar voz activa a los ciudadanos en las decisiones políticas, única manera de lograr resultados concretos en la insurgencia contra el dirigismo estatal de la economía. Y con eso desató el fortalecimiento del Parlamento, el órgano de representación de las fuerzas impulsoras de la sociedad, capaz de frenar los excesos del poder central. La palabra Parlamento es originaria del verbo francés parler, que significa hablar $^{36}$. Luego, designa el local donde se producen conversaciones, discusiones y deliberaciones. Los expertos europeos dicen que el gobierno parlamentario es el gobierno donde se habla.

La cuestión epistemológica de la libre iniciativa pasa por el concepto de lucha de clases, se materializa en las normas de derecho privado sujetas a las codificaciones de los siglos XIX y XX, hasta evolucionar a los cánones de los principios constitucionales y económico-filosóficos.

Es precisamente desde esta perspectiva axiológica (de los principios) que se tratará la libre iniciativa. En términos generales, se puede decir que los principios corresponden a la ideología fundamental del sistema legal. Son ellos los que dan al sistema legal su sentido lógico, armónico, racional y coherente. El principio es un estándar que ha de ser observado, no porque favorezca o asegure una situación económica, política o social que se considera deseable, sino porque es una exigencia de la justicia, la equidad o alguna otra dimensión de la moralidad ${ }^{37}$.

$\mathrm{El}$ análisis de los principios fundamentales de cualquier sistema jurídico, en cualquier rama del derecho, tiene indiscutible importancia práctica: permite la visualización del sistema global para mejorar la aplicación de sus normas. Además,

\footnotetext{
${ }^{36}$ Deutsch, Karl Wolfgang (1976). Politica y gobierno: Cómo el pueblo decide su destino. México D.F.: Fondo de Cultura Económica, p. 198.

${ }^{37}$ Dworkin, Ronald (1989). Los derechos en serio [Taking Rights Seriously]. Guastavino, Marta (Trad.), Barcelona: Ariel Derecho, p. 72.
} 
proporciona una importante ayuda en la comprensión del ordenamiento jurídico, con el objetivo de identificar la coherencia y unidad que hace del cuerpo normativo un verdadero sistema lógico y racional.

La libre iniciativa apareció en la Constitución chilena de 1833, no específicamente con este nombre, porque su comprensión moderna es la libertad de desarrollo de cualquier actividad económica ${ }^{38}$. La Constitución de 1925 trataba del tema en su artículo 10, No 4, inciso $3^{\circ}$, repitiendo el texto de la Carta Política anterior ${ }^{39}$. No obstante, suma a la tutela económica el artículo 10, No $14^{40}$.Por fin, la actual Constitución Política de la República de 1980 establece en su artículo 19, No 21 "el derecho a desarrollar cualquiera actividad económica que no sea contraria a la moral, al orden público o a la seguridad nacional, respetando las normas legales que la regulen. Añade en el artículo 19, No 22 la no discriminación arbitraria en el trato que deben dar el Estado y sus organismos en materia económica".

El alcance de la libre iniciativa se verifica a través de algunos elementos. En primer lugar, presupone la existencia de la propiedad privada, es decir, la apropiación de los bienes y medios de producción. Luego debe existir la libertad de empresa, lo que asegura el libre ejercicio cualquier actividad económica, independientemente de autorización, a excepción de los casos expresamente limitados por la ley. Posteriormente, la libre competencia determina la liberalidad en los precios, con el propósito de generar un entorno competitivo. El último aspecto se refiere a la libertad de contratación, debido al principio de legalidad, por el cual nadie está obligado a hacer o dejar de hacer algo, sino sólo en virtud de una ley ${ }^{41}$.

A través de estas consideraciones se desprende que, al igual que la normatividad afecta a la propiedad, la libre iniciativa no está fuera de las nuevas determinaciones sobre el uso de los bienes privados respetando los contornos sociales.

La Constitución italiana establece la libre iniciativa en su artículo 41, y analizando su contenido reglamentario Francesco GaLGano explica que:

Liniziativa economica privata può dirsi legittima soltanto in quando socialmente utile; e ne hanno tratto la conseguenza che l'utilità sociale costituisce un immediato criterio di valutazione dell'attività dell'imprenditore. Ogni atto di impresa, che sia in contrasto con l'utilità sociale, dovrebbe considerarsi viziato da eccesso di potere: esso potrebbe, su inizia-

\footnotetext{
${ }^{38}$ Artículo 151: "Ninguna clase de trabajo o industria puede ser prohibida, a menos que se oponga a las buenas costumbres, a la seguridad o a la salubridad pública, o que lo esija el interés nacional, i una lei lo declare asi”.

39 "Ninguna clase de trabajo o industria puede ser prohibida, a ménos que se oponga a las buenas costumbres, a la seguridad o a la salubridad pública, o que lo exija el interés nacional y una lei lo declare asî".

40 "La Constitución asegura a todos los habitante de la República (...) la protección al trabajo, a la industria, y a las obras de previsión social, especialmente en cuanto se refieren a la habitación sana y a las condiciones económicas de la vida, en forma de proporcionar a cada habitante un minimo de bienestar, adecuado a la satisfacción de sus necesidades personales y a las de su familia. La ley regulará esta organización".

${ }^{41}$ BARroso, Luis Roberto (2008). "A ordem econômica constitucional e os limites à atuação estatal no controle de preços". Artículo del Juris Plenum Ouro, No 1, mayo de 2008. En: Juris Plenum Ouro, No 18, marzo de 2011. DVD.
} 
tiva di chiunque vanti un interesse legittimo in tal senso, essere annullato dall'autorità giudiziaria ordinaria ${ }^{42}$.

En otras palabras, estamos tratando de un rasgo de la libertad negativa, que es la ausencia de impedimentos para hacer algo y la expansión de la creatividad individual, pero en conjunto con otros factores sociales, que no le permite caracterizarse como un laissez-faire. Así que la libre iniciativa no impide la actividad normativa y reguladora del Estado en beneficio de la colectividad, y para la preservación de los valores constitucionales. En la ausencia de una ley limitadora, la libertad es amplia, y sólo se debe atener a los principios constitucionales ${ }^{43}$.

Sin embargo, vale decir que el beneficio de la colectividad es tan importante cuanto la posibilidad de desarrollarse y usar su creatividad para modificar la producción, generar empleo y renta, explotar y gozar de sus propios bienes; sabiendo que no habrán expropiaciones arbitrarias, que el Estado garantiza la seguridad ciudadana protegiendo las inversiones particulares, que fomenta la atracción de nuevas ideas y tecnologías competitivas y que el capital extranjero tiene cierta seguridad en el mercado nacional. Ese equilibrio es lo que se debe buscar si la finalidad es el desarrollo.

Comprendiéndose que el desarrollo es un fenómeno plural tal cual los conceptos anteriormente estudiados, y que su concretización en el contexto económico depende también de cómo se institucionaliza la tutela de la propiedad y de la libre iniciativa, analizaremos en seguida nuestra noción de desarrollo, para finalmente demostrar cómo debe ser la posición estatal a través del orden económico si se desea caminar hacia esta dirección.

\section{El desarrollo como derecho humano}

Una rápida búsqueda por la palabra "desarrollar" en el diccionario de la Real Academia Española es suficiente para comenzar el problema encontrado en muchas doctrinas sobre el tema. Define la RAE que desarrollar es "acrecentar, dar incremento a algo de orden físico, intelectual o moral, y aun dicho de una comunidad humana: Progresar, crecer económica, social, cultural o politicamente".

La primera definición lleva a la noción de crecimiento, mientras que la segunda, hasta puede parecer una definición más moderna en términos doctrinarios, sin embargo ha utilizado la conjunción disyuntiva "o" para decir crecer económica-

\footnotetext{
${ }^{42}$ Galgano, Francesco (2010). Trattato di diritto civile. Vol. 3, Napoli: Cedam Editore, p. 602. La iniciativa económica privada puede considerarse lícita solamente cuando es socialmente útil; y han llegado a la conclusión de que la utilidad social representa un criterio de evaluación inmediata del empresario. Cada acto de negocio, lo cual es contrario a la utilidad pública, debe considerarse viciado por exceso de poder: eso puede, por iniciativa de cualquiera de las partes con un interés legítimo en este sentido, ser anulado por los tribunales ordinarios. (Traducción del autor).

${ }^{43}$ Tavares, André Ramos (2006). Direito Constitucional Econômico. São Paulo: Método, 2a edición, p. 243. (Traducción del autor).
} 
mente, o crecer culturalmente, o políticamente. Esta conjunción indica alternancia excluyente o exclusiva, lo que es completamente equivocado para una palabra que expresa el progreso multidisciplinar. Esta forma primaria de comprensión del desarrollo fue aclarada por Celso FURTADO ${ }^{44}$ de forma que:

El desarrollo no es sólo un proceso de acumulación y aumento de la productividad macroeconómica, sino principalmente el camino de acceso a formas sociales más aptas para estimular la creatividad humana y responder a las aspiraciones de la colectividad ${ }^{45}$.

La opinión del autor denota la perspectiva plural que debe existir en el desarrollo, siempre considerando los aspectos sociales, políticos, económicos y ambientales conjuntamente. No se puede confundir crecimiento económico con desarrollo, como fue durante tanto tiempo impuesto por la doctrina global.

La carrera por el aumento del PIB en los países -algunas veces enalteciendo su división irreal con indicadores macroeconómicos como el PIB per cápita- es una ciega competencia hacia el "desarrollo". El estudio de indicadores macroeconómicos en este sentido debe considerar todo el conjunto disponible e incluso otros indicadores sociales (como el IDH y el coeficiente GINI) y ambientales (como los desenvueltos por el Programa de las Naciones Unidas para el Medio Ambiente), para así verificar si efectivamente hay desarrollo o no. Ello porque es posible tener buenos ingresos de capital, crecimiento del PIB, pero pésima distribución de renta y altas tasas de inflación. Es posible mostrar crecimiento económico, pero a costa de aumentos incrébles de deuda externa y/o interna. También es posible tener crecimiento, sin aumento inflacionario, sin contracción de deuda externa e interna, pero con extractiva distribución de renta y aumento de degradación ambiental, empeorando la calidad de vida y concentrando la riqueza en las manos de una élite local. Para citar algunos ejemplos.

Del mismo modo, el subdesarrollo no es una etapa por el cual los países que eran llamados de Tercer Mundo deben pasar hasta llegar al soñado desarrollo. La situación económica de los países se debe a la forma como históricamente el poder era ejercido para generar instituciones políticas y económicas inclusivas o extractivas. Según Daron Acemoglu y James Robinson, no es la geografía, cultura o la ignorancia de los pueblos lo que hace una sociedad próspera, sino las instituciones creadas con incentivos básicos que generan la posibilidad de acceso y las ganas de innovar y generar más riqueza ${ }^{46}$. Aunque en nuestra opinión, estos factores (geogra-

\footnotetext{
${ }^{44}$ En 1949 se instaló en Santiago de Chile para trabajar en la recién creada Comisión Económica para América Latina (CEPAL).

${ }^{45}$ Furtado, Celso (2007). "Los desafíos de la nueva generación”. En: Repensar la teoría del desarrollo en un contexto de globalización. Homenaje a Celso Furtado, VIDAL, Gregorio Guillén R., Arturo (Comp.), Buenos Aires: CLACSO.

${ }^{46}$ Acemoglu, Daron y Robinson, James A. (2012). Why Nations Fail? The origins of power, prosperity, and poverty. New York: Crown Publishers, Kindle Edition.
} 
fía, cultura e ignorancia) pueden influenciar aunque mínimamente en este camino, pero no son absolutamente determinantes para justificar la ausencia de progreso.

Estos autores demuestran con ejemplos históricos en todo el globo que las malas decisiones llevan a la estancación, mientras que elegir por la inclusión económica con libertad de acceso a la propiedad, genera incentivos al crecimiento económico enriqueciendo las naciones. Demuestra aún que la concentración de poder y riqueza en manos de pocos hasta puede llevar a un pequeño progreso, pero que es ínfimo en comparación con lo que podría ser generado si las posibilidades fuesen ecuánimes.

Visualmente, esta idea de desarrollo económico, junto a la comprensión de desarrollo plural y sostenible, es muy bien hecha por el triángulo de Peter NijKAMP, en el que cada lado del triángulo representa un objetivo, las flechas ubicadas en los lados representan el sentido del logro de cada uno de los objetivos y el área central del triángulo representa la zona de posible conciliación entre éstos. Dicha zona equivale a la zona de equilibrio para el desarrollo sustentable ${ }^{47}$.

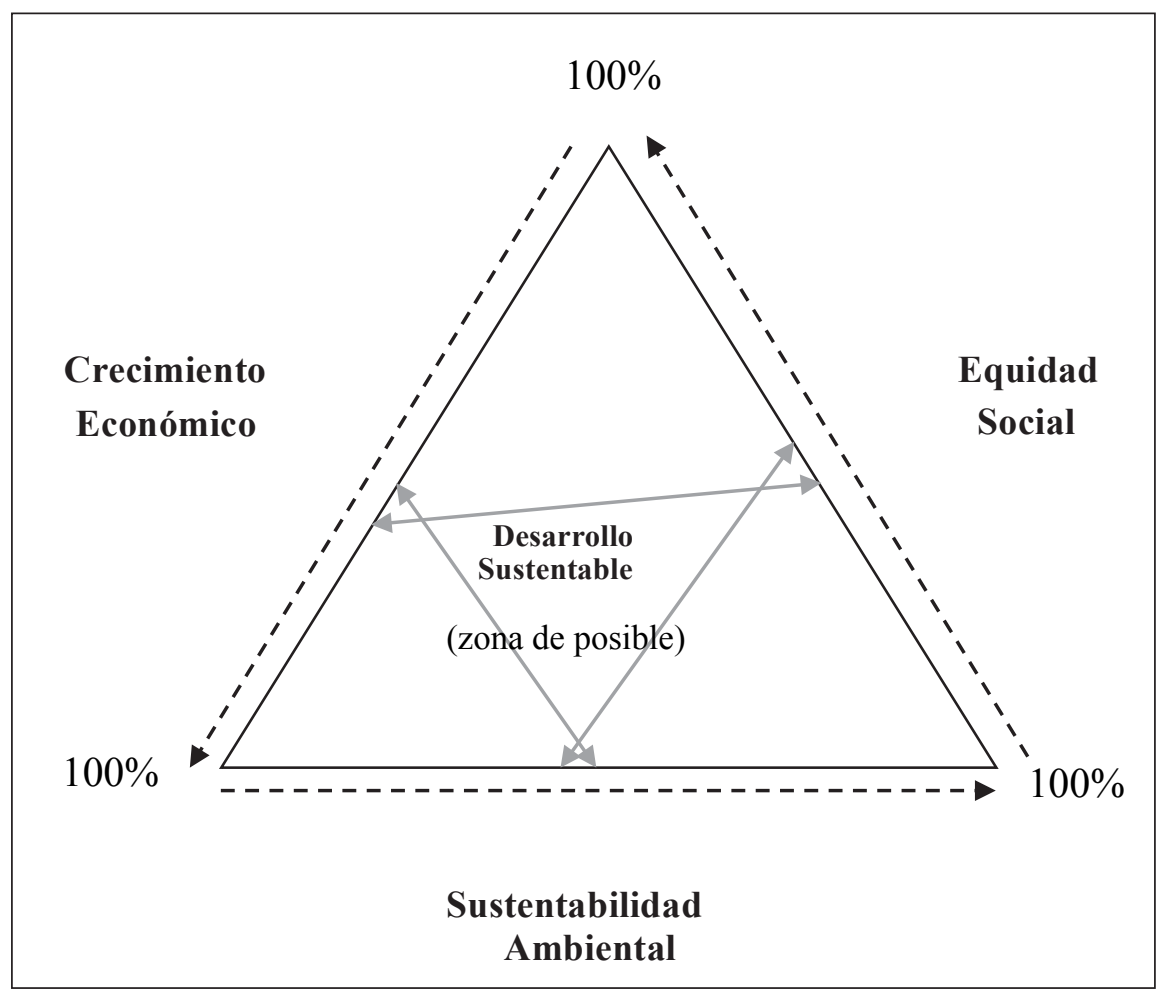

Fuente: adaptado a partir del original de Peter NijKamp, "Regional Sustainable Development and Natural ResourcesUse", World Bank Annual Conference on Development Economics, Washington D.C., 26 y 27 de abril de 1990 .

${ }^{47}$ Dourojeanni, Axel (2000). Procedimientos de gestión para el desarrollo sustentable. Santiago: Naciones Unidas, División de Recursos Naturales e Infraestructura. Disponible en <http://www.redesma.org/ docs_portal/dessost.pdf> [Consulta: 12 septiembre 2013]. 
El tono del derecho económico del desarrollo pasa en gran medida por la dialéctica plural de la sustentabilidad y, como tal, debe conducir a la moderna postura del Estado: como promotor del bienestar; facilitador del diálogo político que es posibilitado a través de la educación -único instrumento que permite la comprensión de la dinámica social, y que posibilita su participación en el gobierno (fundado en la soberanía popular) - y finalmente institucionalizando lo que se considera más importante como valor para la preservación de la sociedad.

Carla RisTER propone tres puntos que deben ser observados por el Estado objetivando el desarrollo: su papel en la redistribución, la difusión de conocimiento económico y la cooperación ${ }^{48}$. Para la autora, una de las funciones del Estado debe ser intervenir con el fin de permitir la redistribución de los ingresos y así proporcionar un acceso equitativo a la población. Con respecto a la difusión del conocimiento económico, se basa en la idea de que la gobernabilidad del sistema económico depende de la interacción de la mayor cantidad posible de interesados, pero advierte que esta interacción sólo sería posible a través de la difusión de los conocimientos sobre los procesos económicos, lo que generaría la igualdad de oportunidades.

RisTeR señala que el ser humano debe ser el centro de todos los procesos sociales, incluyendo el económico. Deja en claro que la dignidad de la persona humana es un valor perseguido por la nación en todos sus segmentos, principalmente el económico. Y así debe ser visto, pero todavía hay cierta distancia de concreción. Obviamente, como ha dicho Rousseau, cuando el hombre renuncia a una parte de su libertad a favor de la tutela del Estado, lo hace con el fin de sus propios intereses. Luego, el que renuncia no podría dejar de lado el fin de desarrollarse como una persona, con referencia a sus propias satisfacciones -lo que obviamente no quiere decir que sólo esta posibilidad debe ser tomada en consideración en el debate sobre el desarrollo.

Esta posición del hombre como un elemento central de la economía es a la par sostenida por Antônio Augusto CANÇADO TRINDADE, afirmando que cabe situar la persona humana en el centro de todo proceso de desarrollo, lo que requiere un mayor espiritu de solidaridad en cada sociedad nacional, y la conciencia de que el destino de cada uno está inexorablemente ligado al destino de todos ${ }^{49}$.

Es indispensable una comprensión holística de los derechos humanos con relación a las determinaciones del escenario económico si se quiere hablar de desarrollo. Exigir el cumplimiento de los derechos económicos, sociales y culturales,

\footnotetext{
${ }^{48}$ Rister, Carla Abrantkoski (2007). Direito ao desenvolvimento: antecedentes, significados e consequências. Rio de Janeiro: Renovar, p. 238.

${ }^{49}$ Cançado Trindade, Antônio Augusto (1995). "Do Direito Econômico aos direitos econômicos, sociais e culturais". En: PLURES. Desenvolvimento econômico e intervenção do Estado na ordem constitucional. Estudos jurídicos em homenagem ao Professor Washington Peluso Albino de Souza, Porto Alegre: Sérgio Antônio Fabris, p. 37. (Traducción del autor).
} 
con el mismo compromiso de los derechos civiles y políticos, es el mecanismo que permitirá la creación de una sociedad libre, justa y solidaria.

En esta propuesta sobre el desarrollo, se puede aclarar aun que la fuerza de su actuación ahora se apoya en otra perspectiva, la de los derechos humanos. Contexto en que el derecho humano es el derecho a tener derechos ${ }^{50}$ concretizados a través de la acción política y que - por su carácter trascendental-va más allá de las fronteras territoriales para recibir atención global.

En 1966 las Naciones Unidas ha proyectado el Pacto Internacional de Derechos Económicos, Sociales y Culturales que entraría en vigor en 1976. En su artículo primero expresa que "todos los pueblos tienen el derecho de libre determinación. En virtud de este derecho establecen libremente su condición politica y proveen asimismo a su desarrollo económico, social y cultural". Establece aun compromisos responsables en la explotación de los recursos naturales y riquezas; medidas de cooperación internacional en materia económica; igualdad entre hombres y mujeres en el acceso de los DESC (derechos económicos, sociales y culturales); normas mínimas laborales y de seguridad social; protección a la familia, salud y medio ambiente; derecho a la educación; y participación en la vida cultural de su nación. Chile ha ratificado este pacto en 10 de febrero de 1972, por lo que incorpora sus disposiciones al ordenamiento interno, y obliga al país a respetar sus determinaciones, independiente de toda la divergencia doctrinaria nacional sobre su estatus en el ordenamiento (como ley, superior a la ley en jerarquía interna, etc.)

Ya en 1986, también por las Naciones Unidas, se establece la Declaración sobre el Derecho al Desarrollo, cuyo eje está en la cooperación mundial para resolver los problemas internacionales de carácter económico, social, cultural o humanitario, y en el desarrollo y estímulo del respeto a los derechos humanos y las libertades fundamentales de $\operatorname{todos}^{51}$. Sus artículos $1^{\circ}$ y $2^{\circ}$ señalan la comprensión fundamental del individuo en la participación económica, y como centro del desarrollo 52 .

\footnotetext{
${ }^{50}$ Cf. Konder, Fábio (1999). A Afirmação histórica dos direitos humanos. São Paulo: Saraiva, p. 215.

${ }^{51}$ Declaración sobre el Derecho al Desarrollo de 1986, adoptado por La Asamblea de las Naciones Unidas a través de la resolución 41/128 de 4 de diciembre de 2006. Disponible en <http://www2.ohchr.org/spanish/ law/desarrollo.htm> [Consulta 16 septiembre 2013].

${ }^{52}$ Artículo 1-1. "El derecho al desarrollo es un derecho humano inalienable en virtud del cual todo ser humano $y$ todos los pueblos están facultados para participar en un desarrollo económico, social, cultural y politico en el que puedan realizarse plenamente todos los derechos humanos y libertades fundamentales, a contribuir a ese desarrollo y a disfrutar del él'.
}

Artículo 1-2. "El derecho humano al desarrollo implica también la plena realización del derecho de los pueblos a la libre determinación, que incluye, con sujeción a las disposiciones pertinentes de ambos Pactos internacionales de derechos humanos, el ejercicio de su derecho inalienable a la plena soberanía sobre todas sus riquezas y recursos naturales".

Artículo 2-1. "La persona humana es el sujeto central del desarrollo y debe ser el participante activo y el beneficiario del derecho al desarrollo". 
El artículo $8^{\circ}$ de la Declaración sobre el Derecho al Desarrollo señala que los Estados deben adoptar, en el plano nacional, todas las medidas necesarias a la realización del derecho al desarrollo y garantizar la igualdad de oportunidades a todos en cuanto al acceso a los recursos básicos, el empleo y la distribución equitativa de los ingresos ${ }^{53}$.

Consecuentemente, el desarrollo debe ser propuesto ampliando el acceso a las libertades subjetivas desde el punto de vista económico, cultural, político y ambiental. Eso significa que a los ciudadanos se les debe ofrecer una variedad de opciones que ellos mismos consideran más importantes con respecto a todos estos aspectos, teniendo en cuenta que todo el trabajo del Estado en la consecución de sus fines es únicamente para la realización del bienestar de sus ciudadanos, y con ello establecer el compromiso de ofrecer la posibilidad de la satisfacción individual y colectiva.

La justificación ontológica del Estado está en la organización de los fines perseguidos por sus ciudadanos y en la reducción de las desigualdades de su entorno. Y como toda comunidad trabaja en favor de su desarrollo, este Derecho Humano crea una perspectiva de valor distinta, teniendo en cuenta la igualdad de oportunidades con relación a los derechos de propiedad, el ambiente satisfactorio a la libre iniciativa, y la regular distribución socioeconómica. Este justo equilibrio es la clave de bóveda para nuestro raciocinio de estructuración abstracta del orden económico, pauteado en los valores demostrados en los capítulos anteriores.

\section{LOS PRINCIPIOS DEL ORDEN ECONÓMICO, EL CAMINO HACIA EL DESARROLLO}

Como hemos visto, el derecho de propiedad y la libre iniciativa no son vistos como antaño. Hoy día están permeados por valores sociales, con los cuales deben coexistir para que las naciones puedan hablar de un justo ambiente facilitador del desarrollo humano. Que debe ser visto de forma plural, respetando el progreso igualitario de las perspectivas económicas, sociales y ambientales de los países. Todas esas cuestiones están derechamente relacionadas con la manera que los países

Artículo 2-2. "Todos los seres humanos tienen, individual y colectivamente, la responsabilidad del desarrollo, teniendo en cuenta la necesidad del pleno respeto de sus derechos humanos y libertades fundamentales, así como sus deberes para con la comunidad, unico ámbito en que se puede asegurar la libre y plena realización del ser humano, y, por consiguiente, deben promover y proteger un orden politico, social y económico apropiado para el desarrollo".

Artículo 2-3. "Los Estados tienen el derecho y el deber de formular politicas de desarrollo nacional adecuadas con el fin de mejorar constantemente el bienestar de la población entera y de todos los individuos sobre la base de su participación activa, libre y significativa en el desarrollo y en la equitativa distribución de los beneficios resultantes de éste".

${ }^{53}$ Este análisis no pierde su valor actual, mismo con otras normas dimanantes de la Organización de las Naciones Unidas, teniendo en cuenta que el derecho al desarrollo y la prosecución de los derechos económicos, sociales y culturales, todavía no es efectivo en las naciones. Luego, nuevas referencias no quitan la importancia de antiguas referencias si se trata de valores no alcanzados. 
estructuran los principios del orden económico, lo que es objeto de estudio del Derecho Económico.

El Derecho Económico, bajo este matiz, debe basarse en las definiciones de Guillermo Cabanellas y Hugo Araneda, donde para el primero, el Derecho Económico es la colección de reglas determinantes de las relaciones jurídicas originadas por la producción, circulación, distribución y consumo de la riqueza ${ }^{54}$. Y para ARANEDA, el derecho económico es aquella rama que regula la intervención del Estado en el proceso económico, en nombre del llamado orden público económico, que es el interés social protegido por el Estado por sobre los intereses particulares, con el fin de realizar el bien común y la justicia social ${ }^{5}$.

Por medio de estas definiciones, encontramos los elementos suficientes a la defensa de nuestra tesis. Primero porque el Estado debe intervenir en la economía (moderadamente, con rasgos correctivos) no solamente como limitador, sino como distribuidor de la riqueza. Después porque los principios del orden económico -responsable por la regulación económica- deben garantizar el interés social en su totalidad.

Empero, dos preguntas deben encontrar sus respuestas en las líneas siguientes, primero ¿cómo debe ser la estructura axiológica de este orden económico? Y después, ¡es difícil encontrar sus reglamentos axiológicos en el ordenamiento jurídico chileno?

-Para contestar a la primera pregunta, los principios que permean el orden económico, que organiza las instituciones responsables por la producción, circulación, distribución y consumo de las riquezas deben, junto con su organización normativa, ser estructurado lo más abstracto posible. Esto se justifica porque la regulación económica debe posibilitar un amplio espectro de actuación política y jurídica, basada en axiomas positivados, que permitan atender a las rápidas demandas del mercado. Como afirma Sandro Amorosino en el prefacio del libro de Cesare San Mauro:

Di tutti i settori della scienza giuridica il diritto dell'economia è quello soggetto alle mutazioni più rapide ed intense, non solo -intuibilmente - in relazione all'evoluzione tecnologica o più in generale agli sviluppi delle economie, ma anche, e specificamente, per le innovazioni delle discipline giuridiche della attività economiche.

Tali innovazioni producono un incessante mutamento di scenari regolari, ai quali devono faticosamente adattarsi le categorie d'analisi dei giuristi dell'economia ${ }^{56}$.

\footnotetext{
${ }^{54}$ Cabanellas, Guillermo (1989). Diccionario Enciclopédico de Derecho Usual. Tomo III. Buenos Aires: Editora Heliasta, 21ª edición, p. 131.

${ }^{55}$ Araneda Dörr, Hugo (1993). Economía Politica. Santiago: Editorial Jurídica de Chile, $3^{a}$ edición actualizada, p. 98.

${ }^{56}$ San Mauro, Cesare (2010). Recenti trasformazioni nel diritto dell'economia. Emilia-Romagna: Maggioli Editore, p. 5. De todas las áreas de la ciencia jurídica, el Derecho Económico es el que está sujeto a mutaciones más rápidas y más intensas, no sólo -intuitivamente- con relación a la evolución tecnológica o, más en general, al desarrollo de las economías, sino también, en particular, por innovaciones de las
} 
El mismo pensamiento tiene el Dr. Carlos Ruiz-Tagle Vial que atribuye al Derecho Económico un carácter dinámico que evoluciona de acuerdo con el desarrollo de conceptos relativos a la equidad y la justicia socia ${ }^{7}$. Afirma aún que su dinamismo $y$ movilidad son elementos esenciales de tal forma que un derecho económico que se estanca es derecho que ha perdido su vitalidad y fuerza, de modo que o se actualiza o sufre la influencia del derecho de otros latitudes que han recogido los aspectos propios del comercio humano, sus nuevas instituciones, instrumentos o vías de comunicación ${ }^{58}$.

Tales instituciones deben generar seguridad ciudadana para que haya confianza de los inversionistas en crear nuevos negocios y adquirir propiedades; deben aún establecer un hito fundamental en las leyes de inversión extranjera, garantizando la seguridad de los inversionistas en su establecimiento en el país, lo que concebirá más empleo y renta, más impuestos recaudados y algunas veces, más acceso a nuevas tecnologías; además, deben proporcionar un buen sistema educacional, para que las personas puedan ser instruidas para desarrollar sus capacidades en favor de la colectividad, a veces creando inventos que puedan cambiar las formas de producción, transporte, salud, viviendas y etc., o del mismo modo haciendo la destrucción creativa (concepto de Joseph SCHUMPETER ${ }^{59}$ ) que permitirá a la nación cambiar la concentración de poder económico, modificando igualmente las demandas por estructuración económica de las instituciones responsables.

El orden económico es una construcción sistemática, compuesto por todas las reglas y principios del ordenamiento jurídico que tienen relación con la regulación económica. El profesor Aimone GIBSON conceptúa que el orden público económico consiste en lograr la conciliación de la realización de los fines de las personas y los fines subsidiarios del Estado. Es el Derecho Público Económico la rama del derecho que, por medio de la técnica de establecer y reconocer derechos fundamentales, de estructurar y delimitar funciones de los organismos a través de los cuales actúe el Estado, consigue esta coordinación de finalidades que hemos designado como orden público económico ${ }^{60}$.

disciplinas jurídicas de las actividades económicas. Estas innovaciones producen un constante cambio en el escenario regular, que debe encajar laboriosamente a las categorías de análisis de la economía legal. (Traducción del autor).

${ }^{57}$ Ruiz-Tagle Vial (2013), p. 33.

${ }^{58}$ Ruiz-Tagle Vial pp. 33 y 34.

${ }^{59}$ (...) las trayectorias tecnológicas y los paradigmas tecnoeconómicos simultáneamente son programas de investigación y desarrollo y modelos, o patrones de conducta a seguir. Si bien otros problemas podrán ser atacados, otras alternativas de solución podrán ser buscadas, otros programas de investigación podrán ser adoptados, siempre estarán al margen de la política principal. Al darse un cambio de paradigma o de trayectoria, algunos o varios de los conocimientos, rutinas e instituciones desarrollados bajo el paradigma anterior se vuelven obsoletos por ser contrarios a las prácticas que ha impuesto la nueva trayectoria o paradigma para poder ser instrumentado. A este reemplazo de conocimiento, rutinas e instituciones es a lo que Joseph A. SCHUMPETER se refería con el original nombre de destrucción creativa. En: Berumen, Sergio A. (2006). Introducción a la economía internacional. Madrid: ESIC Editorial, p. 273.

${ }^{60}$ El concepto de Orden Público Económico de Aimone Gibson es señalado por Arturo Fermandois, aunque el autor chileno no concuerde con dicho concepto. En: Fermandois Vöhringer, Arturo (2011). Derecho 
Desde la Constitución (en las disposiciones sobre propiedad, libre iniciativa, Banco Central, Superintendencia de Valores y Seguros, etc.), el Código Civil (derecho de propiedad y sus garantías, herencia, contratos, etc.), leyes de regulación bancaria (Ley General de Bancos, D.F.L. No 3 de 1997 y Ley Orgánica del Banco Central, No 18.840 de 1989), de protección al consumidor (Ley No 19.496 de 1997), ley de defensa a la libre competencia (D.L. No 211 de 1973), el Código del Trabajo (por el valor de la labor en el desarrollo de las naciones, además de las leyes de seguridad social que garantizan el futuro de los ciudadanos frente a alguna contingencia que los prive de la capacidad laboral, lo que les da sensación de seguridad para ahorrar e invertir), el Código Tributario (ya que establece el costo contributivo de las empresas y personas naturales, y la forma como se utilizarán los tributos recaudados), y los tratados internacionales ratificados por Chile, como el Pacto Internacional de Derechos Económicos, Sociales y Culturales, de todo eso se pueden extraer los valores que componen el orden económico chileno.

Obviamente, si en Chile hubiese un Orden Económico Constitucional, los valores y parámetros interpretativos referentes a la materia estarían mejor identificados, posibilitando encontrar cierta predictibilidad en los fallos judiciales referentes a la materia, y (quizás) mayor seguridad jurídica, teniendo en cuenta que Chile está bajo un sistema jurídico de civil law, donde los precedentes no tienen el mismo papel que en los países del common law. Sin embargo, como no existe este orden público económico delimitado en la CPR de 1980, debemos partir por el concepto de subsidiariedad de todas las normas y principios que guían al jurista en la comprensión de este concepto más amplio ${ }^{61}$.

Esta normativa axiológica más abstracta del ordenamiento jurídico puede ser sintetizada como: principio de libertad económica (CPR artículo 19, No 21, 23 y

Constitucional Económico: Garantías económicas, doctrina y jurisprudencia. Tomo I, Santiago: Ediciones Universidad Católica de Chile, 2a edición actualizada, p. 58.

${ }^{61}$ La constitución brasileña de 1988, por ejemplo, tiene en su Título VII - DEL ORDEN ECONÓMICO Y FINANCIERO. CAPÍTULO I - DE LOS PRINCIPIOS GENERALES DE LA ACTIVIDAD ECONÓMICA. Art. 170. "El orden económico, fundado en la valoración del trabajo humano y en la libre iniciativa, tiene por fin asegurar a todos una existencia digna, de acuerdo con los dictados de la Justicia Social, observando los siguientes principios: 1. soberanía nacional; 2. propiedad privada; 3. función social de la propiedad; 4. libre competencia; 5. defensa del consumidor; 6. defensa del medio ambiente; 7. reducción de las desigualdades regionales y sociales; 8. busca del pleno empleo; 9. tratamiento favorable para las empresas brasileñas de capital nacional de pequeño porte". Párrafo único. "Se asegura a todos el libre ejercicio de cualquier actividad económica, con independencia de autorización de órganos públicos, salvo en los casos previstos en la ley". Art. 172. "La ley disciplinará, con base en el interés nacional, las inversiones de capital extranjero, incentivará las reinversiones y regulará la repatriación de beneficios". Art. 173. "Exceptuados los casos previstos en esta Constitución, la explotación directa de actividades económicas por el Estado sólo será permitida cuando sea necesaria por imperativos de seguridad nacional o de interés colectivo relevante, conforme a la definición de la ley". Art. 174. "Como agente normativo y regular de la actividad económica, el Estado ejercerá, en la forma de la ley, las funciones de fiscalización, incentivación y planificación, siendo esta determinante para el poder público e indicativa para el privado. $1^{\circ}$. La ley establecerá las directrices y las bases de planificación de un desarrollo nacional equilibrado, el cual incorporará y compatibilizará los planes nacionales y regionales de desarrollo. $2^{\circ}$. La ley apoyará y estimulará el cooperativismo y otras formas asociativas. Y otras en el mismo titulo y capitulo". 
24); principio de subsidiariedad del Estado (que carece de reconocimiento expreso, aunque es aceptado por la mayor parte de la doctrina nacional); principio de protección al derecho de propiedad (CPR artículo 19, No 24); principio de igualdad de derecho y oportunidades (CPR artículo 19, No 20); principio de la prohibición de la discriminación arbitraria (CPR artículo 19, No 22); principio de legalidad (CPR artículo 65, No 14 en materia tributaria y artículo 19, No 24 en materia de propiedad); principio del bien común (CPR artículo $1^{\circ}$, inciso $\left.4^{\circ}\right)$; y principio de la primacía de la persona humana $\left(\mathrm{CPR} \text { artículo } 1^{\circ} \text {, inciso } 3^{\circ}\right)^{62}$. Principio de los valores sociales del trabajo (artículo $2^{\circ}$ del Código del Trabajo); principio de protección de la parte más débil en las relaciones de consumo (Ley No 19.496 de 1997); principio de la legalidad tributaria (CPR, artículo 19, No 20, nullum tributum sine lege); y principio de la proporcionalidad e igualdad tributaria (CPR, artículo 19, No 20). Además, sumamos al rol algunos dispositivos del Pacto Internacional de Derechos Económicos, Sociales y Culturales, que forman el principio de la libertad laboral con condiciones justas y favorables (artículos 6 y 7 ), principio del desarrollo personal digno hacia un nivel de vida adecuado (artículos 11 y 13.1), principio de la equidad de gozo de los beneficios del progreso científico (artículo 15), y principio de la protección a los derechos morales y materiales a cualquier descubrimiento científico o artístico (artículo 15), los dos últimos directamente relacionados al derecho de propiedad.

Estos principios son los valores base para cualquier actividad relacionada con el orden económico, sea en el manejo de las leyes existentes por los Poderes del Estado, sea por la actividad legislativa modificadora y/o creadora, por las decisiones judiciales relacionadas con la materia o por la interpretación doctrinaria en la producción científica. Componen el hilo conductor de las instituciones que de alguna manera interfieren en la economía chilena.

Por fin, respondiendo a la segunda pregunta si ¡es difícil encontrar sus reglamentos axiológicos en el ordenamiento jurídico chileno? La respuesta es simple y objetiva: ¡no!

Ya hemos visto anteriormente que existe una serie de normas responsables por otorgar, sobre todo, principios de cómo deben los órganos estatales posicionarse frente a las demandas económicas, sean jurídicas o políticas. Y que teniendo en cuenta toda esta estructura, deberán aún considerar los tratados internacionales de derechos humanos ratificados por Chile (de acuerdo al artículo $5^{\circ}$ de la CPR de 1980), principalmente el Pacto sobre Derechos Económicos, Sociales y Culturales de 1966. Y por qué no decir la Declaración del Derecho al Desarrollo, ya que contiene normas de sugerencia (carácter de soft law ${ }^{63}$ ) con respecto a los derechos humanos, que son universales y de observación obligatoria por todas las naciones.

\footnotetext{
${ }^{62}$ Basado en los principios presentados por Ruiz-TAGLE VIaL (2013), pp. 192-213.

63 "Dare una definizione unitaria ed esaustiva di 'soft law' è molto diffcile, considerando la moltitudine di fenomeni che è possibile ricondurre a questo concetto. In un'eccezione molto generale, possiamo dire che
} 
Estos valores institucionales son más que suficientes para comprender el orden económico como una estructura que prima por los valores sociales en justo equilibrio con el libre uso, goce y disposición de la propiedad que cumple su función social, en la promoción de la libre iniciativa, garantizando que cualquier ciudadano pueda libremente hacer uso de sus bienes para su justo crecimiento. Empero, contando con el Estado en la corrección de las injusticias sociales a través de su gestión participativa, emprendedora y responsable.

En términos prácticos, ¿es posible verificar algún ejemplo donde las instituciones inclusivas y la protección al derecho de propiedad hayan llevado el país al desarrollo? Según Acemoglu y Robinson, en todas partes.

El libro “¿Por qué fracasan las naciones?”, innumerables veces citado en este texto, presenta que desde la historia de la colonización, la protección a la propiedad, la garantía de la libre iniciativa y las sociedades con mayores matices de inclusión, hoy día son las más desarrolladas. A título de ejemplo, veamos lo que ha pasado con Nogales, Arizona, EE.UU. y Nogales, Sonora, México. Son pueblos con la misma etnia, separados por una frontera, provenientes de una misma cultura, que poseen el mismo clima, pero que representan dos caras diferentes del desarrollo, siendo Nogales (EE.UU.) desarrollada y Nogales (México) subdesarrollada.

La explicación viene de cómo EE.UU. ha administrado su parte, ofreciendo la oportunidad de crecimiento a través de la libre iniciativa, la garantía de la propiedad y, obviamente, ofreciendo a sus ciudadanos una sociedad inclusiva, que celebra el esfuerzo personal en la busca del propio progreso.

Éste debe ser el ejemplo a ser seguido por Chile, no efectivamente el ejemplo norteamericano, sino el ejemplo general establecido por los autores de la obra citada. En Chile existe la configuración del derecho de propiedad y de libre iniciativa económica como derechos fundamentales, lo que le falta es el establecimiento de un marco general del Derecho Económico, una Constitución Económica más am-

il termine in questione si riferisce a tutti quei fenomeni di autoregolamentazione diversi dai tradizionali strumenti normativi che sono frutto di un processo formale di produzione legislativa ad opera di organi investiti della relativa funzione. c.d. 'hard law', e la cui caratteristica essenziale è data dal fatto di essere privi di efficacia vincolante diretta. Il termine 'soft law' è tipico del diritto internazionale, nel cui contesto sorge a partire dagli anni '70, anche se è solo negli anni '80 che trova ampia affermazione, sviluppandosi come una sorta di fonte alternativa rispetto ai Trattati internazionali, utilizzata quando per motivi che possono essere i più vari non è possibile ricorrere a questi ultimi”. En: CONVERTI, Antonio (2005). Istituzioni di diritto dell'Unione Europea. Italia: Halley Editrice, p. 184. (Dar una definición unificada y exhaustiva de "soft law" es muy difícil, teniendo en cuenta la multitud de fenómenos que se puede remontar a este concepto. Como excepción muy general, podemos decir que el término en cuestión se refiere a todos los fenómenos de autorregulación diferentes de los instrumentos normativos tradicionales que son el resultado de un proceso formal de producción legislativa a través de órganos investidos en esta función ('hard law'), y cuya característica esencial está dada por el hecho de ser desprovista de eficacia vinculativa directa. El término "soft law" es típico del derecho internacional, cuyo contexto surge a partir de los años 70 , aunque si es sólo en los años 80 que encuentra mayor afirmación, desarrollándose como un tipo de fuente alternativa con respecto a los Tratados Internacionales, utilizado cuando por varias razones no es posible utilizar estos últimos). (Traducción del autor). 
plia, pero abstracta, que simplemente ofrezca el paradigma mínimo (interpretativo, valorativo y limitador a la actividad legislativa y jurídica) que permita construir los cimientos de una economía inclusiva, fuerte y con miras al crecimiento plural colectivo.

\section{CONCLUSIONES}

La propiedad es una de las instituciones más controvertidas de todos los debates académicos. Su concepto, sin embargo, se desarrolló hasta los contornos de la función social, que respeta la libertad colectiva dentro de la misma perspectiva, es decir, la libertad de uno existe hasta el límite de la libertad de los demás, siendo este valor algo elástico, que avanza y se retrae coexistiendo con los otros. Así es la propiedad que tiene una función social, que tiene un propósito que comprende a todos los que con ella se relacionan, propietarios o no.

La exploración de la propiedad se vislumbra a través de la libre iniciativa que permite a cualquier ciudadano el libre uso, goce y disfrute de lo suyo, emprendiendo actividades para su crecimiento, con fines de lucro o no, por el mero hecho de ser dueño de algo. Esta libre iniciativa también está dotada de carácter colectivo, desde el momento que incorpora los valores sociales en su actividad.

Mientras tanto, el Estado está presente y participa de las decisiones del mercado, a través de políticas públicas o de regulación. No es más un mero observador, y debe participar preservando y fortaleciendo los valores más importantes de la sociedad, institucionalizadas por su ordenamiento jurídico, principalmente la dignidad de la persona humana y la ciudadanía.

Exactamente en este punto entra el Derecho Económico, responsable por el diseño del orden económico en sus principios, que irá a establecer las formas de producción, circulación, distribución y consumo de la riqueza; y orientar las decisiones políticas y los fallos judiciales dentro de este paradigma permisivo.

No hay dudas de que el posicionamiento de los Estados en la economía debe ser posibilitar la mayor inclusión social posible, facilitando el acceso a la propiedad, garantizando esta propiedad y su progreso, las inversiones, el acceso al crédito para la promoción de ideas y emprendimientos, pero de la manera más democrática posible.

Las naciones más inclusivas fueron las que generaron más riqueza a lo largo de la historia. Las sociedades extractivas hasta pudieron llegar a un mínimo progreso, aunque esto es ínfimo con respecto a lo que se podría haber generado si fuera abierta e inclusiva. En algunos casos llevaron derechamente a la estancación, simplemente.

Luego, el papel de los principios del orden económico está en garantizar esta sociedad inclusiva, e igualmente, garantizar la corrección de las irregularidades del mercado a través de una actuación discreta y responsable, en búsqueda del justo equilibrio entre la libertad económica y la dignidad colectiva.

Es muy importante que el orden económico favorezca a las instituciones referentes a la propiedad y la libre iniciativa. No hay otra manera de llegar al cre- 
cimiento económico y con este resultado poder ofrecer mejores condiciones de vida a los ciudadanos. Con un resultado económico positivo, es posible generar mejor infraestructura interna, mejores servicios públicos, mejor acceso a las mismas instituciones jurídico-económicas tuteladas por el derecho y luego, crear un círculo virtuoso que siga caminando hacia el desarrollo.

No obstante, este desarrollo debe llevar -en la medida de lo posible- sus tres elementos en conjunto: progreso social, económico y ambiental. O tendremos crecimiento, progreso o cualquier otra cosa, menos desarrollo.

No hay otro camino que comprender estos conceptos, no hay otra posibilidad que la convergencia de los programas gubernamentales para su concretización, de lo contrario, a corto plazo, puede haber un gran estancamiento social, generando crisis como las que se observaron en muchos países desde el 2008, lo que demuestra que la riqueza nacional no tiene valor si la riqueza de los valores no reemplaza el concepto de crecimiento por el de desarrollo.

\section{BiBLIOGRAFÍA CITADA}

AвATI, Riccardo (2012). Storia dei diritti umani. Padova: GOODmood, 1 edizione. Acemoglu, Daron y Robinson, James A. (2012). Why Nations Fail? The origins of power, prosperity, and poverty. New York: Crown Publishers, Kindle Edition.

Aldunate Lizana, Eduardo y Fuentes Olmos, Jessica (1997). "El concepto de derecho de propiedad en la jurisprudencia constitucional chilena y la teoría de las garantías del instituto". En: Revista de Derecho de la Pontificia Universidad Católica de Valparaíso, Vol. XVIII, pp. 195-221.

Alessandri Rodríguez, Arturo (1937). Derecho Civil. Tomo II, Santiago: Zamorano y Caperán.

Alexander, Gregory y Peñalver, Eduardo (2012). An introduction to property theory. Cambridge: Cambridge University Press.

AlmeIDA, Washington (2006). Direito de propriedade: limites ambientais no código civil. Barueri (São Paulo): Manole.

Araneda Dörr, Hugo (1993). Economía Política. Santiago: Editorial Jurídica de Chile, $3^{\text {a }}$ edición actualizada.

Areitio Rodrigo, Ramón (1996). Derecho Natural. Lecciones elementales. Bilbao: Universidad de Deusto, Serie Publicaciones de la Universidad de Deusto.

Azambuja, Darcy (2001). Teoria Geral do Estado. São Paulo: Editora Globo.

BArroso, Luis Roberto (2008). "A ordem econômica constitucional e os limites à atuação estatal no controle de preços”. Artículo del Juris Plenum Ouro, No 1, mayo de 2008. En: Juris Plenum Ouro, No 18, marzo de 2011. DVD.

Berumen, Sergio A. (2006). Introducción a la economía internacional. Madrid: ESIC Editorial.

Cabanellas, Guillermo (1989). Diccionario Enciclopédico de Derecho Usual. Tomo III. Buenos Aires: Editora Heliasta, 21 $1^{\text {a }}$ edición. 
Caldera, Rafael (1981). "Código Civil de la República de Chile”. En: Obras completas de Andrés Bello, Tomo XIV, Caracas: Fundación La Casa de Bello.

Cavedon, Fernanda de Salles (2003). Função social e ambiental da propriedade. Florianópolis: Momento Atual.

Comparato, Fábio Konder (1999). A Afirmação histórica dos direitos humanos. São Paulo: Saraiva.

Converti, Antonio (2005). Istituzioni di diritto dell'Unione Europea. Italia: Halley Editrice.

CoOter, Robert y Ulen, Thomas (2008). Derecho y economía. México: Fondo de Cultura Económica, 2a edición.

Cordero Quinzacara, Eduardo (2006). "La dogmática constitucional de la propiedad en el derecho chileno". Revista de Derecho (Valdivia), Vol. 19, No 1, pp. 125-148. Disponible en: <http://www.scielo.cl/scielo.php?pid=S071809502006000100006\&script $=$ sci_arttext $>$ [Consulta 30 diciembre 2013].

Deutsch, Karl Wolfgang (1976). Política y gobierno: Cómo el pueblo decide su destino. México D.F.: Fondo de Cultura Económica.

Dourojeanni, Axel (2000). Procedimientos de gestión para el desarrollo sustentable. Santiago: Naciones Unidas, División de Recursos Naturales e Infraestructura. Disponible en <http://www.redesma.org/docs_portal/dessost.pdf> [Consulta: 12 septiembre 2013].

Dworkin, Ronald (1989). Los derechos en serio [Taking Rights Seriously]. GuastaVINO, Marta (Trad.), Barcelona: Ariel Derecho.

FARJAT, Gérard (1982). Droit Economique. Paris: Presses Universitaires de France, 2e édition.

Fermandois Vöhringer, Arturo (2011). Derecho Constitucional Económico: Garantías económicas, doctrina y jurisprudencia. Tomo I, Santiago: Ediciones Universidad Católica de Chile, $2^{\text {a }}$ edición actualizada.

Furtado, Celso (1974). O mito do desenvolvimento econômico. Río de Janeiro: Paz e Terra.

Furtado, Celso (2007). "Los desafíos de la nueva generación”. En: Repensar la teoría del desarrollo en un contexto de globalización. Homenaje a Celso Furtado, Vidal, Gregorio y Guillén R., Arturo (Comps.), Buenos Aires: CLACSO.

Galgano, Francesco (2010). Trattato di diritto civile. Vol. 3, Napoli: Cedam Editore.

Liguori, Alfonso (2009). "La teoria dei diritti fondamentali di Luigi Ferrajoli: Considerazioni epistemologiche e politiche”. In: Jura Gentium. Rivista di filosofia del diritto internazionale e della politica globale. Disponible en: <http:// www.juragentium.org/topics/rights/it/liguori.htm> [Consulta: 15 enero 2014].

PACHECO, Wellington (1984). "A propriedade agrária e seu novo conceito jurídico constitucional”. Revista Ajuris (Associação dos Juizes do Rio Grande do Sul), No 32, Año XI, Porto Alegre: Ajuris. 
Prado D., Maximiliano (2007). "Limitación de los Derechos Humanos: Algunas consideraciones teóricas". Revista Chilena de Derecho, Vol. 34, No 1, pp. 61-90. Disponible en: <http://www.scielo.cl/scielo.php?script=sci_ arttext\&pid=S0718-34372007000100005\&lng=es\&nrm=iso > [Consulta: 15 enero 2015].

PúPeri, Cyro Luiz Pestana (2008). "A função social, econômica e a preservação do meio ambiente como condiçôes limitadoras do direito de propriedade". Artículo del Juris Plenum Ouro, No 1, mayo de 2008. En: Juris Plenum Ouro, No 18, marzo de 2011. DVD.

Rister, Carla Abrantkoski (2007). Direito ao desenvolvimento: antecedentes, significados e consequências. Rio de Janeiro: Renovar.

Rocha OchOA, Cesáreo (2006). Manual de introducción al derecho. Colección Lecciones de jurisprudencia, Bogotá: Editorial Universidad del Rosario, $1^{\text {a }}$ edición.

Ruiz-Tagle Vial, Carlos (2013). Curso de Derecho Económico. Santiago: Librotecnia: $2^{a}$ edición actualizada y aumentada.

SAn Mauro, Cesare (2010). Recenti trasformazioni nel diritto dell'economia. EmiliaRomagna: Maggioli Editore.

Silva Otero, Aristídes (2005). La llamada revolución industrial. Caracas: Universidad Católica Andrés Bello.

Tavares, André Ramos (2006). Direito Constitucional Econômico. São Paulo: Método, 2a edición.

Trindade, Antônio Augusto Cançado (1995). "Do Direito Econômico aos direitos econômicos, sociais e culturais". En: PLURES. Desenvolvimento econômico e intervenção do Estado na ordem constitucional. Estudos jurídicos em homenagem ao Professor Washington Peluso Albino de Souza, Porto Alegre: Sérgio Antônio Fabris. 